\title{
Supplying Innovation?: Investigating Impact of Suppliers on Innovation in IT Firms
}

\author{
Ashish Kumar Jha \\ Supply Chain and IS Department \\ Rennes School of Business \\ Rennes, France \\ Email: ashish-kumar.jha@rennes-sb.com

\section{Indranil Bose} \\ Management Information Systems Department \\ Indian Institute of Management Calcutta \\ Kolkata, India \\ Email: bose@iimcal.ac.in
}

\begin{abstract}
Although IT has been widely recognized as one of the most important determinants of the innovation in firms yet the determinants of innovation within IT firms are very poorly understood. Higher cooperation with various players is widely believed to be an important determinant of innovation productivity. The players include suppliers, clients, competitors, universities etc. Amongst these supplier is a very intriguing class of partners more so because of its importance for manufacturing firms and almost a negligible presence in IT literature. We attempt to understand what impact a closer cooperation with suppliers has in innovation productivity in IT firms. Literature from traditional manufacturing firms' domain indicates that suppliers are very integral to innovation processes at a firm. Our research drawing from data of Chinese firms finds that suppliers are indeed a very critical determinant of IT innovation as well. The results from this paper sheds considerable light on suppliers and their integral role for IT firms' innovation development.
\end{abstract}

Keywords: Innovation, IT firms, China, Suppliers, Cooperation 


\section{Introduction}

The rapid advances in technology and knowledge is making it increasingly difficult for firms to be selfreliant in adapting to these advances. Firms are increasingly looking beyond their own boundaries for knowledge and skills which complement their capabilities (Becker \& Dietz, 2004). These collaborations are an effort to augment their offerings to their clients and stay competitive in rapidly evolving market. Various types of cooperative innovation efforts are prevalent today which includes vertical collaboration with suppliers or with clients and horizontal collaboration with partners or even competitors. Many of these cooperative innovation techniques have got a lot of attention of academicians and practitioners alike and cooperation of some sort is considered as essential component of innovation program of firms (Chesbrough \& Teece, 1996).

Various studies have analyzed multiple aspects of cooperation in innovation productivity at firms and presented frameworks addressing the issues related to innovation management in cooperative innovation regimes. However, most of these works focus on manufacturing firms and services firms have not been studied in similar depth (Tether \& Tajar, 2008). This fact is in stark contrast to the world's overall productivity today which is predominantly a service dominant. Understanding the dynamics of service industries and the impact of higher innovation due to various types of cooperative arrangements thus becomes an important research topic.

In our current work we attempt to understand the dynamics of a specific cooperation effort on innovation outcome. We analyze the impact for IT firms, which constitute a dominant segment of service industry today, more so for developing countries. IT itself has been credited to being one of the most important tools for innovation productivity (Davenport, 2013), a typical innovation enabler. But the intricacies of innovation processes within IT firms are not so well understood (Bharadwaj, 2000). Manufacturing literature unequivocally argues that suppliers are one of the most important cooperation partners for increasing innovation (Bidault, Despres, Butler, 1998; Freel, 2003); however the concept of suppliers is a bit shaky in terms of modern IT firms. For IT product manufacturing firms, the traditional supplier definition and its understanding remains the same, however for services firms the term supplier generally refers to partners who provide inputs as services, knowledge or hardware for information processing. Another important aspect with IT firms is the prevalence of process innovations. In this paper we attempt to evaluate the impact of suppliers on innovation productivity of IT firms to take the innovation literature a step further and provide results applicable to a typical service sector firm in addition to existing manufacturing literature.

A second aim is to analyze the impact specifically in context of a developing economy. Liefner, Hennemann \& Xin (2006) in their work on product innovation found that finer intricacies of developing new products differ in developing economies from the developed economies on account of different processes ingrained in the firm's collective culture. In our work we aim to extend this debate further on cooperation decisions in IT firms.

To this end, we empirically investigate the impact that coordination with suppliers has on IT firms' innovation outcomes. The results are based on analysis of Chinese firms' data provided by World Bank Enterprise Survey (Enterprise Survey, 2012). The analysis has been performed for both product and process innovation in IT firms. The results indicate that suppliers are very critical enablers for both these types of innovation. The results emerging out of analysis of Chinese firms do not vary too significantly from the earlier works based on manufacturing firms of Europe. The rapid rate of advancement in technology is present everywhere and coordination with suppliers to evolve more innovative products and service is a coping mechanism which has been adopted in different economies.

In the next section we present a brief overview of the extant literature of the field. This is followed by the data and its statistical analysis in the next section. In subsequent sections, we analyze the result and discuss its implications for academics and practitioners alike before concluding in final section. 


\section{Literature Review}

Firm level cooperation is increasingly been considered as an important determinant in firm's survival and success in todays networked economies (Abramovsky et al., 2008). Innovation is no exception to this trend and cooperative firms have been found to have higher R\&D intensity (Sampson 2007). Increase in R\&D intensity is not the only determinant leading to higher amount of cooperation amongst firms. Belderbos et al (2003) found in their work that higher cooperation increases firms' profitability from R\&D activities. R\&D activities, as is commonly known, are very resource intensive and cooperation amongst firms helps in sharing resources, investments along with knowledge thus increasing the success of these efforts while considerably reducing costs for the firms. One more aspect in the increasing clamor for cooperation in innovation is the influx of new perspectives to cater to higher demand for innovation from market. Various firms have consistently increased their R\&D investments to create innovation units to develop new products for their customers and clients and external input in such efforts increases the outcome significantly. These factors also elucidate why the high technology intensive industries have a higher concentration of cooperative innovation (Miotti \& Sachwald, 2003).

Cohen and Levinthal (1989) state that external input in a firm's organizational knowledge building capabilities is of significantly higher impact as the firm's internal R\&D abilities increase. Due to these factors firms increasingly see innovation partnerships and sourcing of such innovation inputs being complementary to their own efforts and not as substitutes (Adams \& Marcu, 2004; Arora \& Gamberdella, 1990). Firms invest in their own innovation unit development and also source a significant amount of knowledge from different kinds of partners including other firms, universities, independent R\&D units etc.

While sourcing information from cooperation partners a game theoretic situation often emerges where each of the constituent partners of the innovation network aims to maximize their respective takeaways from the cooperation network. The amount of knowledge that an organization can appropriate within its organizational knowledge depends on its absorptive capacity (Cohen \& Levinthal, 1989). Given the delicate nature of the cooperation arrangements possible, firms cooperate to create new knowledge when the aimed innovation outcome is not only new either of the participating firms but to the market itself (De Faria, Lima \& Santos, 2010). Such arrangement ensures higher gain for all collaborating parties with minimum unwanted spillover of internal knowledge of firms.

Schmidt (2005) throws more light on this perspective in the decision to cooperate for firms on matters of $\mathrm{R} \& \mathrm{D}$ and innovation. This is the effort to maintain a balance between high knowledge growth via external acquisition and maintaining secrecy of the information internal to the firm. It is in these context that a firm choses to cooperate with partners seen as very reliable for the focal firm. Thus reliability, trust and mutual benefit are very important constructs defining the possible partners for a firm. Based on these factors a firm may ally with one of the two kinds of knowledge alliance partners to develop innovation networks. These are either to increment the focal firm's existing knowledge base and build on its platform or to develop entirely new knowledge base by producing a radical shift in its innovation paradigm (De Faria, Lima \& Santos, 2010; Bercovitz \& Feldman, 2007).

Given these factors, it seems only natural that firms' would collaborate with other firms whose interests are closely tied to the focal firm and which might not be a potential competitor in the industry. Attallah (2002) also finds that gains from vertical spillovers with collaborators up or down the supply chain like suppliers or clients have higher impact on focal firm's R\&D performance than horizontal collaborations with other firms. Belderbos, Carree \& Lokskin (2004) also states that cooperation with suppliers help a firm in increasing not only its R\&D productivity but also its labor productivity.

In light of this discussion, suppliers do seem to be one of the most important research cooperation partners. Various studies have independently corroborated the fact that suppliers are very important cooperation partner to achieve higher R\&D productivity (Becker \& Dietz, 2004; Belderbos et al, 2006; Cassiman \& Veugelers, 2002; Quintana-farcia \& Benavides-Velasco, 2004). While for manufacturing firms the impact of suppliers on the focal firm is well understood, not so much is known for services sector including IT firms. This research focuses on this gap to analyze the impact of supplier cooperation on IT firms and we base our analyses on Chinese firms' data to draw our conclusions. 


\section{Data and Results}

The data set used in this research is the Enterprise Survey Data that is obtained from the World Bank. We have used data for year 2012 which is the latest year for which the data is available for firms in China. The innovation survey, which is conducted by the World Bank as a part of the Enterprise Survey, is designed using the guidelines that are provided in the Oslo manual for innovation (Oslo Manual, OECD Publishing, 1997). These surveys are conducted physically by World Bank representatives and are made available for use by researchers around the world on request.

For Chinese firms the analysis is performed on privately held as well as publicly traded firms. We exclude the state owned Chinese firms as these firms tend to invest disproportionately in research to uphold the public commitment of the government (Heath, 2013). Hence, such firms may not be a true representative of the firms that practice innovation in China.

For China the total number of IT firms is 290. These firms can be designated as small, medium and large firms on the basis of their employee count. The distribution criterion that is used is as follows: small firms have between 5 and 19 employees, medium firms have between 20 and 99 employees and large firms have more than 100 employees. This definition is adopted from the World Bank's definition of firm size. Table 2 provides a detailed breakup of the sample according to firm size (i.e., in terms of number of employees of the firm). Table 1 shows the summary descriptive statistics for the major variables used in this research. We use natural logarithms of the financial variables. The variable firm revenue is the revenue of the firm in the preceding financial year. The other two variables that are listed include the expenses internal and external R\&D activities by the firms.

\begin{tabular}{|c|c|c|}
\hline & \multicolumn{2}{|c|}{ China } \\
\hline Firm size & $\underline{\text { Freq. }}$ & Percentage \\
\hline Small $>=\mathbf{5}$ and $<=\mathbf{1 9}$ & 107 & $36.90 \%$ \\
\hline Medium $>=\mathbf{2 0}$ and $<=\mathbf{9 9}$ & 102 & $35.17 \%$ \\
\hline Large $>=\mathbf{1 0 0}$ & 81 & $27.93 \%$ \\
\hline Total & 290 & \\
\hline
\end{tabular}

Table 1: Distribution of Chinese firms in the dataset according to firm size

\begin{tabular}{|c|c|c|c|c|}
\hline Variable & Mean & Std. Dev. & Min. & Max \\
\hline Firm revenue & 16.69 & 1.69 & 12.33 & 22.11 \\
\hline $\begin{array}{c}\text { Average annual spend on } \\
\text { intramural R\&D }\end{array}$ & 14.02 & 1.51 & 11.51 & 18.42 \\
\hline $\begin{array}{c}\text { Average annual spend on } \\
\text { contracted R\&D }\end{array}$ & 12.47 & 3.58 & 0 & 15.42 \\
\hline
\end{tabular}

Table 2: Descriptive statistics of properties for Chinese firms

All values are natural logarithms of respective values in US\$.

Table 1 and Table 2 show the firm distribution by size and their descriptive statistics respectively for Chinese IT firms. The data shows that the same is proportionate amongst small, large and medium firms and do not have any disproportionate representation. Table 2 also shows that for the expenditure on intramural $R \& D$ activities is greater than that on contracted $R \& D$ activities.

In our current work we test both product and process innovation separately for the impact of supplier cooperation since various studies have indicate fundamental differences in the way product and process innovations unfold at organization (Fritsch \& Meschede, 2001; Avermaete et al., 2004). We have created logistic regression models to test these impacts. 
Our dependent variables are product and process innovations which are binary variables. These variables are set to 1 for firms which have introduced a product or process innovation in last full year for survey (2011). The primary explanatory variable for our research is use of suppliers as innovation cooperation partners. The variable is also a binary variable which is set to 1 if suppliers were one of the major innovation cooperation partners for the firm's surveyed.

A host of control variables are necessary in any regression based analysis to understand the impact of the explanatory variable under the impact of existing variables. We have used the following variables as control variables for the purpose to analyze the impact of suppliers under their constraints:

a. Firm Revenue: Revenue of a firm is the indicator of its size and thus its agility as well. It is one of the factors which can have a huge impact of firm's innovation capability. This is because innovation requires investment and larger firms would have higher capacity to invest in multiple processes for enhancing innovation. Firms that are smaller in terms of revenue have fewer resources to invest in multiple simultaneous activities (Tsai, 2001; Damanpour, 1991). In our current work to make the formulation linear, we have used natural logarithms of the firm's revenue as the variable.

b. Internal R\&D Spending: Expenditure on research and development is another critical control variable employed in this paper. Internal R\&D spending is an indicator for processes set within the firm for enhanced innovation productivity (Parthasarathy \& Hammond, 2002; Sampson, 2007). It is also an indicator of the kind of innovation activity that firm promotes. Here again, we have used the natural log of R\&D expenses as a control variable.

c. External R\&D Spending: External R\&D through licensing, procurement or contracted R\&D is another important innovation style. Many firms indulge in this style of innovation primarily, though most firms use a mix of both internal and external R\&D methods Parthasarathy \& Hammond, 2002; Sampson, 2007). It is also an indicator of the kind of innovation activity that firm promotes in terms of bringing out of the box ideas for the firm from outside the firm's knowledge base. Here also, we have used the natural log of R\&D expenses as a control variable.

d. Firm Age: Firm's age is a signifier of both its legacy and maturity which defines how much agility the firm has in producing innovative products and processes (Almus \& Nerlinger, 2006; De Jong \& Vermeulen, 2006; Cefis \& Marsili, 2006). That is particularly because lot of studies have concluded that younger firms are more agile with respect to use of new technology and thus on this account they tend to be more innovative than old and established firms (Baldwin \& Lin, 2002; Heunks, 1998).

e. Workforce using computers: One of the most important determinants of innovation in the digital age and more so in IT firms is the widespread use of IT within the firm. Various researches have established that workforce with higher access to digital resources are more suited to innovate rapidly (King, 2006; Zahra \& George, 2002). The data has been used to control for firm's affinity for technology which might affect the way newer processes are introduced in firms and hence ability to align with suppliers' interests at all levels. The data is the percentage of workforce which actively uses computers in their day to day activities at the surveyed firms.

Table 3 given below shows the correlation matrix of all the variables being analyzed in the paper as discussed above

\begin{tabular}{|c|c|c|c|c|c|c|c|c|}
\hline & & 1 & 2 & 3 & 4 & 5 & 6 & 7 \\
\hline 1 & Product Innovation & - & & & & & & \\
\hline 2 & Process Innovation & $(0.105)^{* *}$ & - & & & & & \\
\hline 3 & Firm age & $(0.041)^{*}$ & $(0.042)$ & - & & & & \\
\hline 4 & Firm revenue & $0.143^{* *}$ & $0.147^{* *}$ & $(0.022)$ & - & & & \\
\hline
\end{tabular}




\begin{tabular}{|c|c|c|c|c|c|c|c|c|}
\hline 5 & $\begin{array}{c}\text { Internal R\&D } \\
\text { spending }\end{array}$ & $0.143^{* *}$ & $(0.205)^{* *}$ & $(0.048)$ & $0.578^{* *}$ & - & & \\
\hline 6 & $\begin{array}{c}\text { External R\&D } \\
\text { spending }\end{array}$ & 0.092 & $(0.333)^{* *}$ & $(0.194)^{*}$ & $(0.600)^{* *}$ & $0.807^{* *}$ & - & \\
\hline 7 & $\begin{array}{c}\text { Workforce using } \\
\text { computers }\end{array}$ & $0.0791^{* *}$ & $(0.020)$ & $(0.027)$ & $(0.037)$ & $0.105^{* *}$ & $(0.108)$ & - \\
\hline 8 & $\begin{array}{c}\text { Innovation in } \\
\text { cooperation with } \\
\text { suppliers }\end{array}$ & $(0.035)$ & $0.202^{* *}$ & $(0.018)$ & $(0.059)^{*}$ & 0.007 & $(0.169)^{*}$ & $(0.067)^{* *}$ \\
\hline
\end{tabular}

Table 3: correlation matrix of the variables of the study

${ }^{*} \mathrm{p}<0.05,{ }^{* *} \mathrm{p}<0.01 ; \quad($ ) denotes a negative number.

To analyze the impact of supplier cooperation on product and process innovation, we perform two different analyses, one with product innovation as dependent variable and another with process innovation as the dependent variable. For both these analyses, we create two different models. In the first model we have the dependent variables being regressed against the control variables to get a base result. We introduce the explanatory variable of suppler cooperation in model 2 in both the analyses and then analyze the impact it has on the overall results.

All the four models were highly significant with chi square values of all four tests being less than 0.01. Thus the tests were significant at $99 \%$ levels. The explanatory power being provided by the tests is also sufficiently high which increases in both cases after the addition of the variable for supplier cooperation.

The tables 4 and 5 given below show the results of the analyses as obtained.

\begin{tabular}{|c|c|c|c|c|c|c|}
\hline & \multicolumn{3}{|c|}{ Model 1} & \multicolumn{3}{|c|}{ Model 2} \\
\hline & Coefficient & Std. Error & P-Value & Coefficient & Std. Error & P-Value \\
\hline Firm age & 0.019 & 0.012 & 0.464 & 0.011 & 0.017 & 0.328 \\
\hline Firm revenue & -0.185 & 0.111 & 0.44 & -0.237 & 0.174 & 0.484 \\
\hline Internal R\&D spending & 0.17 & 0.013 & 0.032 & 0.385 & 0.087 & 0.042 \\
\hline External R\&D spending & 0.247 & 0.086 & 0.007 & 0.279 & 0.093 & 0.004 \\
\hline Workforce using computers & -0.006 & 0.005 & 0.18 & -0.002 & 0.001 & 0.21 \\
\hline $\begin{array}{c}\text { Innovation in cooperation } \\
\text { with suppliers }\end{array}$ & - & - & - & 0.316 & 0.0847 & 0.005 \\
\hline Power of test (chi square) & \multicolumn{3}{|c|}{0.000} & \multicolumn{3}{|c|}{0.000} \\
\hline Log Likelihood ratio & \multicolumn{3}{|c|}{-143.647} & \multicolumn{3}{|c|}{-159.475} \\
\hline _hat & 0.805 & 0.237 & 0.003 & 0.918 & 0.447 & 0.002 \\
\hline _hatsq & 0.178 & 0.029 & 0.048 & 0.057 & 0.034 & 0.098 \\
\hline
\end{tabular}

Table 4: Logit results for product innovation at Chinese IT firms

\begin{tabular}{|c|c|c|c|c|c|c|}
\hline & \multicolumn{3}{|c|}{ Model 1 } & \multicolumn{3}{c|}{ Model 2 } \\
\hline & $\underline{\text { Coefficient }}$ & $\underline{\text { Std. Error }}$ & $\underline{\underline{p-V a l u e}}$ & $\underline{\text { Coefficient }}$ & $\underline{\text { Std. Error }}$ & $\underline{\underline{p-\text { Value }}}$ \\
\hline Firm age & 0.103 & 0.174 & 0.664 & 0.115 & 0.123 & 0.628 \\
\hline Firm revenue & -0.249 & 0.128 & 0.39 & -0.198 & 0.119 & 0.372 \\
\hline
\end{tabular}




\begin{tabular}{|c|c|c|c|c|c|c|}
\hline Internal R\&D spending & 0.299 & 0.081 & 0.002 & 0.283 & 0.091 & 0.002 \\
\hline External R\&D spending & 0.361 & 0.152 & 0.041 & 0.349 & 0.146 & 0.048 \\
\hline Workforce using computers & -0.008 & 0.041 & 0.271 & -0.007 & 0.031 & 0.313 \\
\hline $\begin{array}{c}\text { Innovation in cooperation } \\
\text { with suppliers }\end{array}$ & - & - & - & 0.125 & 0.043 & 0.031 \\
\hline Power of test (chi square) & \multicolumn{3}{|c|}{0.000} & \multicolumn{3}{c|}{0.000} \\
\hline Log Likelihood ratio & \multicolumn{3}{|c|}{-148.947} & & & \\
\hline _hat & 0.712 & 0.149 & 0.002 & 0.692 & 0.158 & 0.002 \\
\hline _hatsq & 0.214 & 0.113 & 0.871 & 0.341 & 0.247 & 0.957 \\
\hline
\end{tabular}

Table 5: Logit results for process innovation at Chinese IT firms

\section{Analysis and Discussion}

The logistic regression model results shown in table 4 and 5 throw some interesting results for analysis. For product innovation as well as process innovation it can be readily seen that the model is a very good fit for the data as evident by the Chi square value and its log likelihood ratios. The explanatory power has increased from model 1 to model 2 for both product and process innovation indicating the significance of supplier cooperation as an important variable for both product and process innovation. The analysis also indicates some interesting points where the product and process innovation paradigms slightly differ from each other. The results indicate that firm age and firm revenue are not a significant determinant for either the product or process innovation. These results are in line with prior research in this field which has more or less remained inconclusive on the impact of these two variables on innovation productivity. Internal R\&D spending is a significant determinant of product $\mathrm{R} \& \mathrm{D}$, although at $95 \%$ significance level but for process innovation internal R\&D gains much higher prominence. It has a higher coefficient value at $99 \%$ significance level. The percentage of workforce using computers is not a significant determinant for any of the innovation models. One of the important reasons for this result is the fact that use of computers in IT firms is highly ubiquitous and use of computing resources in no way impacts the innovation outcome as it did in early years of IT boom. The results are consistent across both the innovation styles.

Adding our primary explanatory variable of supplier cooperation to the model 1 to receive model 2, we get that supplier cooperation is a significant determinant of innovation productivity for both product and process innovation. However, the results also indicate that supplier cooperation is much is much more significant for product innovation than it is for process innovation. This is consistent with the control variables which indicate that external $R \& D$ to be more significant for product innovation while internal $\mathrm{R} \& \mathrm{D}$ to be more significant for process $\mathrm{R} \& \mathrm{D}$.

The following post estimation tests were performed to check for the robustness of the logit regressions performed

a. Specification Test:- Specification test was performed to test the power of the models. The results as depicted in the last 2 rows of table 4 and 5 indicates that the model is correctly specified. The values for linear predicted value (_hat) are found to be statistically significant for all models. The values for linear predicted value square (_hatsq) were also within acceptable ranges indicating that model was not misspecified or that any variable was not omitted.

b. Classification Test:- Classification test of the models indicated that in all the 4 models constructed there is no classification error. The percentage correctly classified for both the product innovation models are $88.24 \%$ and $89.49 \%$ and the corresponding values for process innovation models are $89.76 \%$ and $90.33 \%$.

Both these tests indicate the robustness of the test and the correct specification of the models. 
These results are extremely significant from point of view of both academicians and practitioners alike. Establishing the fact that suppliers are important partners for increasing innovation productivity, either product or process, for even IT firms extends the literature on innovation cooperation to IT firms. Managers at IT firms can better evaluate the possible tie-ups with the vertical partners in their effort to remain highly innovative and in turn competitive in the industry.

\section{Conclusion}

Although suppliers as a construct itself is very poorly understood and very faintly recognized for services firms and in particular for IT firms, the results show that they are important players in enabling higher innovation productivity. In times when higher innovation is the need of the hour and most firms have dedicated teams to find ways to improve innovation productivity, increased understanding of the innovation determinants would enable the managers at such firms to deploy better programs aimed at increasing innovation productivity. The results have been reached after a careful analysis of data of Chinese IT firms.

The results established in this paper are not without its own limitations. The generalizability of the result may be limited and a wider empirical investigation from different geographies needs to be conducted to establish the same. More exploratory works and cases from various firms indulging in innovation through supplier cooperation needs to be performed, to better understand the dynamics behind these. One more factor that needs to be explored in this domain is the impact of multinational firms vs. local firms and the impact of diversified supplier network on the innovation productivity.

However, even with its own limitations, the results of this paper are important, as it establishes the importance of suppliers and enables both practitioners and academicians to see the various cooperation partners as important determinant for IT innovations. The fact that suppliers are crucial innovation partners in both product and process innovations at IT firms shows the importance in sectors beyond traditional manufacturing. These results in this paper extend the extant literature in IS on determinants of various types of innovation. The importance of suppliers as a cooperation partner for fostering higher innovation indicate the impact of cooperation decisions in the domain of IT innovations.

\section{References}

Abramovsky, L., Kremp, E., López, A., Schmidt, T., and Simpson, H., 2008. "Understanding co-operative R\&D activity: evidence from four European countries". Economics of Innovation and New Technology

Adams, J., and Marcu, M., 2004. R\&D sourcing, joint ventures and innovation: a multiple indicators approach. NBER Working Paper, 10474.

Almus, M., and Nerlinger, E. A. 1999. "Growth of New Technology-Based Firms: Which Factors Matter?”. Small Business Economics. (13:2), pp. 141-154.

Arora, A., and Gambardella, A., 1990. Complementarity and external linkages: the strategies of the large firms in biotechnology. Journal of Industrial Economics.(38:4), pp. 361-379

Atallah, G., 2002. "Vertical R\&D spillovers, cooperation, market structure, and innovation". Economics of Innovation and New Technology . (11:3), pp. 179-209.

Avermaete, T., Viaene, J., Morgan, E. J., Pitts, E., Crawford, N., and Mahon, D. 2004. "Determinants of product and process innovation in small food manufacturing firms". Trends in Food Science \& Technology, 15(10), 474-483.

Baldwin, J., and Lin, Z. 2002. "Impediments to Advanced Technology Adoption for Canadian Manufacturers". Research Policy. (31:1), pp. 1-18.

Becker, W., and Dietz, J. 2004. " $R \& D$ cooperation and innovation activities of firms-evidence for the German manufacturing industry". Research policy, (33:2), pp. 209-223.

Belderbos, R., Carree, M., Diederen, B., Lokskin, B., and Veugelers, R., 2003. "The determinants of R\&D cooperation: evidence from Dutch CIS Data 1996-1998”. ZEW Workshop on the Empirical Economics of Innovation and Patenting, Mannheim, Germany, March pp. 14-15.

Belderbos, R., Carree, M., and Lokskin, B., 2004. "Cooperative R\&D and firm performance". Research Policy. (33:10), pp. 1477-1492. 
Belderbos, R., Carree, M., and Lokshin, B. 2006. "Complementarity in R\&D cooperation strategies". Review of Industrial Organization, (28:4), pp. 401-426.

Bercovitz, J., and Feldman, M., 2007. Fishing upstream: firm innovation strategy and university research alliances. Research Policy (36:7), pp. 930-948.

Bidault, F., Despres, C., and Butler, C. 1998. "The drivers of cooperation between buyers and suppliers for product innovation". Research Policy, (26:7), pp. 719-732.

Bharadwaj, A. S. 2000. "A Resource-Based Perspective on Information Technology Capability and Firm Performance: An Empirical Investigation”. MIS Quarterly, (24:1), pp. 169-196.

Cassiman, B., and Veugelers, R. 2002. "R\&D cooperation and spillovers: some empirical evidence from Belgium”. American Economic Review, pp. 1169-1184.

Cefis, E., and Marsili, O. 2006. "Survivor: The Role of Innovation in Firms' Survival". Research Policy, (35:5), pp. 626-641.

Chesbrough, H. W., and Teece, D. J. 1996. "When is virtual virtuous". Harvard business review, (74:1), pp . 65-73.

Cohen, W., and Levinthal, D., 1989. Innovation and learning: the two faces of R\&D. The Economic Journal. (99:397), pp. 569-596

Damanpour, F. 1991. "Organizational Innovation: A Meta-Analysis Of Effects of Determinants and Moderators". Academy Of Management Journal, (34:3), pp. 555-590.

Davenport, T. H. 2013. "Process Innovation: Re-Engineering Work Through Information Technology". Harvard Business Press.

De Faria, P., Lima, F., and Santos. R. 2010. Cooperation in innovation activities: The importance of partners. Research Policy. (39:2008). Pp. 1082-1092

De Jong, J. P., and Vermeulen, P. A. 2006. "Determinants of Product Innovation In Small Firms A Comparison Across Industries". International Small Business Journal, (24:6), pp. 587-609.

Freel, M. S. 2003. "Sectoral patterns of small firm innovation, networking and proximity". Research policy, (32:5), pp. 751-770.

Fritsch, M., and Meschede, M. 2001. "Product innovation, process innovation, and size". Review of Industrial Organization, (19:3), pp. 335-350.

Heath, J. (Ed.). 2013. "Public Enterprise at The Crossroads". Routledge.

Heunks, F. J. 1998. "Innovation, Creativity and Success". Small Business Economics., (10:3), pp. 263-272.

King, W. R. 2006. "IT strategy and innovation: Recent innovations in knowledge management”. Information Systems Management, (24:1), pp. 91-93.

Liefner, I., Hennemann, S., and Xin, L. 2006. "Cooperation in the innovation process in developing countries: empirical evidence from Zhongguancun, Beijing”. Environment and Planning A, (38:1), pp. 111.

Miotti, L., and Sachwald, F., 2003. Cooperative R\&D: why and with whom? An integrated framework of analysis. Research Policy (32:8), pp. 1481-1499.

OECD. 1997. "The Measurement of Scientific and Technological Activities Proposed Guidelines for Collecting and Interpreting Technological Innovation Data: Oslo Manual”. OECD Publishing.

Parthasarthy, R., and Hammond, J. 2002. "Product Innovation Input and Outcome: Moderating Effects of the Innovation Process". Journal of Engineering and Technology Management, (19:1), pp. 75-91.

Sampson, R., 2007. "R\&D Alliances and firm performance: the impact of technological diversity and alliance organization on innovation”. Academy of Management Journal. (50:2), pp. 364-386

Schmidt, T. 2005. Knowledge flows and R\&D co-operation: firm-level evidence from Germany. ZEW Discussion Paper, pp. 05-22.

Tether, B. S., and Tajar, A. 2008. "The organisational-cooperation mode of innovation and its prominence amongst European service firms". Research policy, (37:4), pp. 720-739.

Tsai, W., 2001. "Knowledge Transfer in Intra-organizational Networks: Effects of Network Position and Absorptive Capacity on Business Unit Innovation and Performance". Academy of Management Journal, (44:5), pp. 996-1004

Quintana-Garcia, C., and Benavides-Velasco, C. A. 2004. "Cooperation, competition, and innovative capability: a panel data of European dedicated biotechnology firms". Technovation, (24:12), pp. 927938.

Zahra, S. A., and George, G. 2002. "The net-enabled business innovation cycle and the evolution of dynamic capabilities”. Information Systems Research,(13:2), pp. 147-150. 


\section{Acknowledgements}

The authors like to thank the World Bank Enterprise survey for providing access to firm level micro data for this research to be completed (Enterprise Survey). The authors like to state that all inferences drawn in the paper and all views presented are authors' own and are in no way representative of World Bank's views or inferences.

\section{Copyright}

Copyright: (C) 2018 Jha \& Bose. This is an open-access article distributed under the terms of the Creative Commons Attribution-NonCommercial 3.0 Australia License, which permits non-commercial use, distribution, and reproduction in any medium, provided the original author and ACIS are credited. 